\title{
Near infrared spectroscopy for assessing mechanical properties of Castanea sativa wood samples
}

\author{
Manuela Mancini, ${ }^{1}$ Elena Leoni, ${ }^{1}$ Michela Nocetti, ${ }^{2,3}$ Carlo Urbinati, ${ }^{1}$ Daniele Duca, ${ }^{1}$ Michele Brunetti, ${ }^{2}$ \\ Giuseppe Toscano ${ }^{1}$
}

${ }^{1}$ Department of Agriculture, Food and Environmental Sciences, Polytechnic University of Marche, Ancona, Italy;

${ }^{2}$ Institute of BioEconomy, Sesto Fiorentino (FI), Italy; ${ }^{3}$ Department of Forest and Wood Science, Stellenbosch

University, Stellenbosch, South Africa

\begin{abstract}
Near infrared spectroscopy (NIR) is a technique widely used for the prediction of different chemical-physical features of wood. In this study, the technique was used to assess its potential to predict the mechanical characteristics of wood. Castanea sativa samples of three different European provenances were collected and laboratory tests were performed to assess the mechanical properties of wood samples. Modulus of elasticity (MOE), load-deflection curve and modulus of rupture (MOR) were calculated by using INSTRON machine with three points bending strength with elastic modulus, while density (D) was calculated according to the current standard. Samples were then analysed by means of NIR spectroscopy. The raw spectra were pre-processed and regression models were developed. Variables selection techniques were used to improve the model performance. In detail, MOE regression model returned an error of 696.01 MPa $\left(\mathrm{R}^{2}=0.78\right)$. Instead, MOR and D prediction models must be further investigated on a wider number of samples considering the high variability in physical characteristics of chestnut wood. The results demonstrated the possibility to use NIR technique for the prediction of the mechanical properties of wood providing useful indications in evaluation-screening processes. Indeed, the presence of the principal wood compounds (cellulose, hemicellulose and lignin) and their influence in the characterisation of mechanical stress reactions were confirmed
\end{abstract}

\footnotetext{
Correspondence: Giuseppe Toscano, Department of Agriculture, Food and Environmental Sciences (D3A), Polytechnic University of Marche, via Brecce Bianche, I-60131 Ancona, Italy.

Tel.: +39.0712204917.

E-mail: g.toscano@staff.univpm.it
}

Key words: Modulus of elasticity; partial least square regression; variables selection; chemometrics; chestnut wood.

Received for publication: 19 March 2019.

Accepted for publication: 23 August 2019.

(C) Copyright: the Author(s), 2019

Licensee PAGEPress, Italy

Journal of Agricultural Engineering 2019; L:953

doi:10.4081/jae.2019.953

This article is distributed under the terms of the Creative Commons Attribution Noncommercial License (by-nc 4.0) which permits any noncommercial use, distribution, and reproduction in any medium, provided the original author(s) and source are credited.

\section{Introduction}

Innovative investigations on timber properties demonstrate that physical features (density and organic tissue morphology) and mechanical characteristics (modulus of elasticity and rupture and ultimate compression strength) are closely related to chemical features (Kelley et al., 2004; Sandak et al., 2013). This aspect is particularly exploited in near infrared spectroscopy (NIR) applications for the determination of qualitative and quantitative parameters of wood (Tsuchikawa and Kobori, 2015).

NIR spectroscopy allows the chemical and physical characterisation of wood and organic matter, and the assessment and prediction of its mechanical properties. NIR radiation, interacting with sample organic components, assesses absorbance energy spectra. The NIR spectrum is characterised by overtone and combination of fundamental chemical bonds $(\mathrm{O}-\mathrm{H}, \mathrm{C}-\mathrm{H}, \mathrm{N}-\mathrm{H})$, recognised by amplified molecular vibration due to excitation (Yu et al., 2009; Toscano et al., 2017).

NIR spectroscopy is not a new technique since it was used for the first time around 1960 (Tsuchikawa and Kobori, 2015). The advantages of this method are several; in fact, the analysis results to be rapid, simple, non-destructive and also cheap. Fourier transform (FT)-NIR could require a quick sample preparation, while NIR analysis not requires sample preparation at all, making it very suitable also for field utilisation.

The applications are numerous and reported by several authors (Tsuchikawa and Kobori, 2015). Wood components as lignin, cellulose and extractives are key variables to discriminate the species by physical and mechanical characteristics (Sandak et al., 2013). The successful use of NIR is also given by the high correlation between mechanical and chemical wood features (Guo and Altaner, 2018). The investigation on modulus of elasticity (MOE), cellulose content and the inverse relation with micro-fibril angle showed high correlation in Pinus taeda analysis (Kelley et al., 2004). On the other hand, particle size and wood moisture content influenced lignin and monosaccharides content prediction in Pinus radiata (Fahey et al., 2018). The study of wavelengths associated to more influential chemical components on Aspen tremuloides samples revealed high correlation with mechanical characteristics, defined by high coefficients of determination (Horvath et al., 2011). Compressive and bending strength properties and density effects have been assessed on larch hybrids (Fujimoto et al., 2007), underlining the use of NIR to classify wood by mechanical quality (Tsuchikawa and Kobori, 2015). Specific MOE and modulus of rupture (MOR) values were analysed for Chinese wood provenance, like Cunninghamia lanceolata, but the use of NIR was suggested only for visual screening (Yu et al., 2009). Other studies have attempted to predict residual mechanical properties 
after wood degradation by microbial activity. An appreciable correlation of MOE and MOR values between intact samples and decayed ones was detected (Barré et al., 2018). Another NIR application concerned the moisture content analysis of six different Eucalyptus species: the prediction of mechanical resistance was determined through the detection of $\mathrm{O}-\mathrm{H}$ bonds in absorbance spectra (Pfautsch et al., 2012). Moreover, the investigation on structural and thermal characterisation of lignin was demonstrated to be related to chemical compounds presence revealed on surface wood at specific wavelengths (Watkins et al., 2015).

Considering the importance to certify woody material, this study aims to evaluate the performance of NIR technology for the assessment of MOE, MOR and density in chestnut (Castanea sativa Mill.) wood. The main purpose focuses on the validation of regression models by means of NIR spectroscopy technique for the prediction of the mechanical properties of chestnut wood samples from different geographic provenances. In addition, variables selection methods were applied to improve the model performance. Chestnut is a long-living and fast-growing hardwood species, with high agamic reproductive capacity and high timber quality. Its wood is ring porous, solid, flexible (Nocetti et al., 2016), rich in tannins, which makes it naturally durable. Besides the possible formation of ring-shake, it is considered a multipurpose wood: from energy wood to the production of small-medium size fencing poles or other assortment for soil and water bioengineering, to structural timber and flooring (Macchioni and Pividori, 1996).

\section{Materials and methods}

\section{Collection and preparation of wood samples}

A total of 150 wood samples of Castanea sativa from three different provenances was collected as 50 samples $\times 3$ sites: Northern France (NFR), in Normandy (districts 61, 27, 14 and 28), Southern Italy (SIT), in the north part of Aspromonte and in the south of Sila, and Central Italy (CIT), in the area of Acquasanta, Amatrice, Campotosto and Scandarello. Samples were defect-free wood strips obtained from boards and were $42 \mathrm{~cm}$ long with a square cross-section of $2 \mathrm{~cm}$. The equilibrium moisture content was maintained around $12 \%$ after natural drying in sawmill and with suitable packing during transportation between the different laboratories.

\section{Laboratory analysis}

The mechanical measurements were carried out at CNR-IVALSA of Sesto Fiorentino (Italy) by using INSTRON equipment. MOE and MOR were determined by three points bending tests, according to ISO/FDIS 13061 Physical and mechanical properties of wood - Test methods for small clear specimen, part 3 (MOR) and 4 (MOE). The linear portion of the load-deflection curve $(\mathrm{P})$ was calculated as the slope of the linear portion of the load-deflection curve. Samples were stabilised at $12 \%$ of moisture content and density (D) was calculated according to ISO/FDIS 13061, part 2.

All the samples were numbered and coded in accordance to provenances. A symbol was added to each sample to indicate the ring direction relative to load movement: perpendicular, parallel or at $45^{\circ}$ angle, according to the natural shape of timber. Each sample was positioned on the two external supports at a distance of 280 $\mathrm{mm}$ and the load was applied at the mid-span with a constant rate of movement of the loading cell until rupture of the test specimen. For the calculation of MOE, P was also considered.

\section{Near-infrared analysis}

NIR analysis was carried out to the residual parts of the samples, so to the unaffected parts remaining after their reduction for density test. The 150 wood sample portions had different lengths, but on average around $15 \mathrm{~cm}$. The NIR analysis was performed at the Biomass Lab of the Department of Agriculture, Food and Environmental Sciences (D3A), UNIVPM with a FT-NIR spectrophotometer (FT-NIR mod, Nicolet iS10, THERMO, Massachusetts, United States) equipped with an integrative sphere. Spectra were acquired in the wavelengths range from 10,000 to $4000 \mathrm{~cm}^{-1}$ with the spectral resolution of $8 \mathrm{~cm}^{-1}$ and 32 scans. During the acquisition a continue nitrogen flow was used to reduce moisture content inside the instrument, so to minimise results variability. For each sample four replicates were collected on four different points of sample surface: two measurements were performed on the compression part (where load has fallen) and two on traction part (the opposite face of the sample). The sample position on the acquisition window was chosen by the operator to avoid low pressure areas, grains and identification signs of the sample ID. A background spectrum was collected after each sample and was used to subtract the entire electromagnetic signal to control and reduce the environmental variability.

\section{Chemometrics}

Multivariate data analysis was used to extract useful information from the spectral dataset. In detail, principal component analysis (PCA) and partial least square regression (PLS) (Wold and Sjostrom, 1977) models were developed. PCA was performed in order to explore the spectral variability and search for samples grouping in accordance to the different provenances. PLS models were developed to predict MOE, MOR and D. To improve model interpretation and to minimise noise as irrelevant information of variability due to the nature of the material, spectra were pre-treated (Rinnan et al., 2009). In detail, different pre-treatments including standard normal variate, multiplicative scatter correction, first and second derivatives (Savitzky-Golay algorithm) with 9, 13 and 21 smoothing points and a combination of the previous ones were applied. PLS models were validated using venetian blind crossvalidation (10 cancellation groups). $\mathrm{R}^{2}$ (coefficient of determination), root mean square error of cross validation (RMSECV), slope and bias were accounted to evaluate the model performance. The different regression models were also compared using range error ratio (RER) and ratio of performance to deviation (RPD) indices. According to literature, RPD values should range between 2 and 4 for good prediction, and $>4$ for excellent quality control (Sørensen, 2009). Instead, RER values should range between 7 and 20 for screening application, and become $>20$ for good prediction (Fagan et al., 2011). Considering the huge number of samples analysed, PLS models were also validated using an external test set. The dataset was split using Kennard-Stone algorithm: 105 samples were used as training set and the remaining 45 samples as test set.

The variable selection techniques have a couple of advantages: i) performance improvement of the prediction model, which become more reliable and solid; ii) facilitation and speeding of the model interpretation (Norgaard et al., 2000; Rinnan et al., 2014). In this study, for all the wood parameters considered, several variable selection techniques were tested: variable important in prediction (Wold et al., 2001), recursive weighted partial least squares (rPLS) (Rinnan et al., 2014) and interval partial least squares (iPLS) (Norgaard et al., 2000). iPLS was tested using both forward and backward methods with two interval sizes (50 and 100 segments). Subsequently, PLS models were computed again after 
applying the best variable selection method. Calculations were performed in Matlab (ver. 7.10.0, The MathWorks) using in-house functions based on existing algorithms.

\section{Results and discussion}

\section{General statistical analysis}

The general descriptive statistics of the physical and mechanical parameters analysed (MOE, MOR and D) were summarised in Table 1. The correlations between the several properties were medium-low: MOE displayed a correlation of $\mathrm{R}^{2}=0.54$ with $\mathrm{MOR}$ and of 0.20 with $\mathrm{D}$; MOR and D correlated also poorly $\left(\mathrm{R}^{2}=0.34\right)$. Similar results have been observed after full-scale tests on structural material. A poor correlation is linked to problems in grading timber strength characteristics and it was confirmed especially for hardwood and chestnut wood (Brunetti et al., 2013; Nocetti et al., 2016). In particular with chestnut wood, density was correlated to strength resistance properties according to ring widths during growth (Romagnoli et al., 2014). In literature, better values for mechanical characteristics evaluation were obtained using softwood samples (Sousa et al., 2014).

\section{Principal component analysis}

PCA was performed on the spectral dataset pre-treated using different techniques. None of the tested pre-treatments has showed a samples separation in accordance to the three different provenances. Figure 1 reports the PCA score plot of the dataset pre-treated with first derivative as an example. It is possible to note a homogeneous distribution of the samples in the PCA space demonstrating the high spectral similarities among the three samples provenances.

\section{Prediction of modulus of elasticity}

Different pre-treatments were tested and the ones returning satisfactory predictions were reported in Table 2 . The best results were obtained using the first derivative Savitzky-Golay method with 21 points window (second-order polynomial). The best prediction model used $8 \mathrm{LVs}$ and gave back RMSECV=813.14 $\mathrm{MPa}$ and $\mathrm{R}^{2}=0.70$.

In-depth analyses on the best selected model allowed to identify possible sample or replicate outliers. An x-y replicate outlier was found on the observed vs predicted response plot. By repeating PLS computation the model performance improved, obtaining the following results: i) RMSECV decreased from 813.14 to 783.10 $\mathrm{MPa}$; ii) steady number of LVs; and iii) $\mathrm{R}^{2}$ increased from 0.70 to 0.72 . RER and RPD indices were also computed to appraise the model performance. Removing the replicate outlier, RER increased from 9.50 to 9.86 and RPD from 1.82 to 1.89 , indicating the model fitness as a screening tool for quality control applications. Figure 2A shows the regression plot of the developed model and Figure $2 \mathrm{~B}$ the most important wavelengths for the prediction of MOE.

There are no relevant peaks between 10,000 and $7500 \mathrm{~cm}^{-1}$ (Figure 2B). Spectra oscillation become wider between 7500 and $6000 \mathrm{~cm}^{-1}$ but only from 6000 to $4000 \mathrm{~cm}^{-1}$ they provide valuable information. Peaks at 6002 (1) and 4675 (3) $\mathrm{cm}^{-1}$ are mostly related to $\mathrm{C}-\mathrm{H}$ vibrations (Table 3 ), whereas different bands are assigned to $\mathrm{O}-\mathrm{H}$ stretching, corresponding to the peaks at 4436 (4) and 4204 (7) $\mathrm{cm}^{-1}$. Instead, bands at 4910 (2), 4382 (5) and 4104 (8) $\mathrm{cm}^{-1}$ are assigned both to $\mathrm{O}-\mathrm{H}$ and $\mathrm{C}-\mathrm{H}$ vibrations bonds. Peaks at $6002(1), 4910$ (2) and $4382(5) \mathrm{cm}^{-1}$ are related to cellulose and hemicellulose, peak at $6002(1) \mathrm{cm}^{-1}$ is principally related to lignin, while peaks at 4675 (3) and $4436(4) \mathrm{cm}^{-1}$ are related both

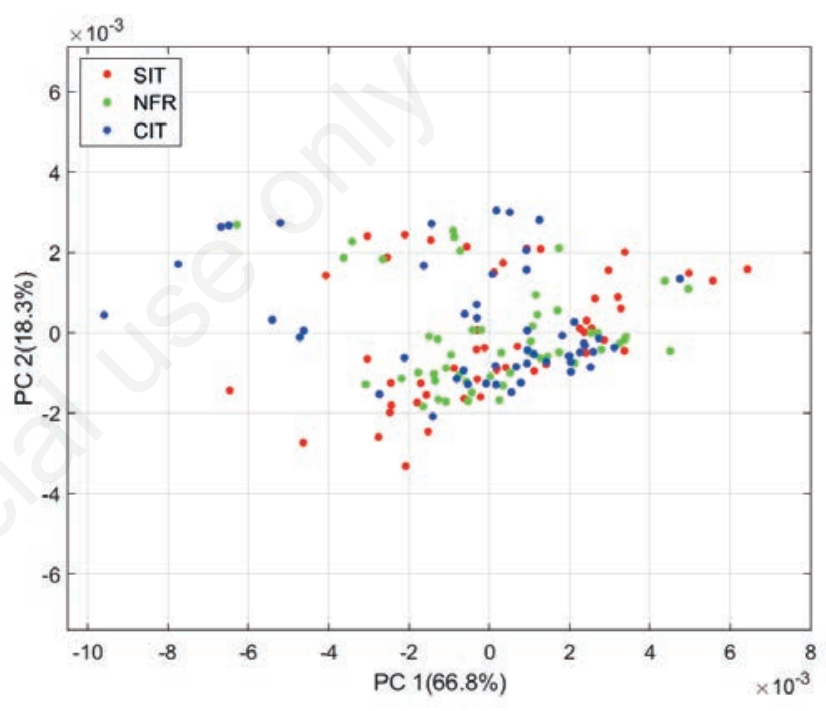

Figure 1. Principal component analysis (PCA) score plot of the two first PCs. Northern France (NFR), Southern Italy (SIT), Central Italy (CIT).

Table 1. General descriptive statistics of the chestnut samples.

\begin{tabular}{lccc} 
& MOE $(\mathrm{MPa})$ & MOR $(\mathrm{MPa})$ & $\mathrm{D}\left(\mathrm{kg} / \mathrm{m}^{3}\right)$ \\
Mean & 12132 & 102.4 & 548 \\
Standard deviation & 1464 & 12.5 & 32 \\
\hline Min & 7231 & 65.8 & 480 \\
Max & 14956 & 121.2 & 639
\end{tabular}

MOE, modulus of elasticity; MOR, modulus of rupture; D, density.

Table 2. Summary of partial least squares prediction results for modulus of elasticity (MPa). The best model values are in italics.

\begin{tabular}{lccccccc} 
& LVs & RMSECV & $R^{2}$ & Slope & Bias & RER & RPD \\
No pre-treatment & 6 & 981.98 & 0.57 & 0.4962 & -19.2022 & 7.87 & 1.51 \\
SNV & 7 & 899.71 & 0.64 & 0.5682 & -15.9431 & 8.59 & 1.65 \\
\hline 21der2 & 5 & 916.32 & 0.62 & 0.5895 & -5.2914 & 8.43 & 1.62 \\
21der 1 & 8 & 813.14 & 0.70 & 0.6768 & 13.5735 & 9.50 & 1.82 \\
\hline
\end{tabular}

LVs, number of latent variables; RMSECV, root mean square error of cross validation; RER, range error ratio; RPD, ratio of performance to deviation; SNV, standard normal variate; 21 derl, first derivative with 21 number of smoothing points; 21der2, second derivative with 21 number of smoothing points. 
to cellulose and lignin. These results are consistent with the literature and confirmed that the characteristic wavelengths useful for predicting the mechanical properties are mainly those attributed to cellulose (Kelley et al., 2004; Fujimoto et al., 2007; Tsuchikawa and Kobori, 2015).

The best PLS model for the prediction of MOE was also validated using an external test set. It was developed pre-treating the data with first derivative (Savitzky-Golay method, 21 points window, second-order polynomial) and using 7 LVs. It returned RMSECV=731.34 MPa, R ${ }^{2}=0.71, R M S E P=1019.80 \mathrm{MPa}, \mathrm{R}^{2}$ (pred) $=0.71, \mathrm{RPD}=1.23$ and $\mathrm{RER}=7.25$. The indices pointed out a fair model that could be used for rough screening quality applications to discern between high and low MOE values.

\section{Variables selection}

Different variables selection methods were applied to MOE prediction models. Table 4 reports the figure of merit of the full model and the PLS models on the reduced wavelengths range. Forward iPLS (100 segments) resulted the best variable selection method. For MOE prediction, $\mathrm{R}^{2}$ increased from 0.72 to 0.78 and RMSECV value decreased from 783.10 to $696.01 \mathrm{MPa}$. Good results were reported also comparing RER and RPD values: RER increased from 9.86 to 11.10 and RPD from 1.89 to 2.13 , enhancing the potential use of the model for quality screening control. Similar results were obtained also using forward iPLS (50 seg- ments) and rPLS demonstrating the feasibility of the two variables selection techniques to be used for improving the model performance.

iPLS selected relevant variables in different part of the spectra, including wavelengths higher than $6000 \mathrm{~cm}^{-1}$ (Figure 3), even if previous analysis on regression vector plot has showed the absence of important wavelengths until $6000 \mathrm{~cm}^{-1}$.

The region between 9000 and $7500 \mathrm{~cm}^{-1}$ is assigned to $1^{\text {st }}$ and $2^{\text {nd }}$ OT of C-H stretching vibrations from carbohydrates (methyl and methylene groups) and lignin (Schwanninger et al., 2011). Instead the region between 7500 and $6000 \mathrm{~cm}^{-1}$ is assigned to $1^{\text {st }}$ OT of C-H combination bands and $1^{\text {st }}$ OT of O-H stretching vibrations. The region between 6000 and $5400 \mathrm{~cm}^{-1}$ is related to all wood compounds and in particular to $1^{\text {st }}$ OT of the aliphatic and aromatic C-H stretching vibrations (Schwanninger et al., 2011; Popescu and Popescu, 2013). Most of the variables selected are in the last part of the spectra. The region between 5400 to $4500 \mathrm{~cm}^{-1}$ is dominated by $\mathrm{C}=\mathrm{O}$ groups and, $\mathrm{O}-\mathrm{H}$ stretching and deformation vibrations and $\mathrm{C}_{\mathrm{ar}}-\mathrm{H}$ and $\mathrm{C}-\mathrm{H}$ stretching vibrations. The region between 4500 and $4000 \mathrm{~cm}^{-1}$ is mostly related to $\mathrm{C}-\mathrm{H}$ stretching and $\mathrm{C}-\mathrm{H}$ deformation vibrations (Schwanninger et al., 2011; Popescu and Popescu, 2013).

The variables selected in the MOE pre-processed spectra are mainly related to cellulose, followed by hemicellulose and lignin. In detail cellulose is present mainly from 4787 to 4017 (13) $\mathrm{cm}^{-1}$

Table 3. Assignment of infrared absorption bands in the regression vector plot of modulus of elasticity.

\begin{tabular}{|c|c|c|c|c|c|}
\hline & $\begin{array}{c}\text { Measured } \\
\text { wavenumber }\left(\mathrm{cm}^{-1}\right)\end{array}$ & $\begin{array}{c}\text { Literature } \\
\text { wavenumber }\left(\mathrm{cm}^{-1}\right)\end{array}$ & Compound & Assignment & Reference \\
\hline 1 & 6002 & $\begin{array}{l}6003 \\
6002\end{array}$ & $\begin{array}{l}\mathrm{H} \\
\mathrm{L}\end{array}$ & $\begin{array}{l}1^{\text {st }} \text { OT C-H str. } \\
1^{\text {st OT Car-H str. }}\end{array}$ & $\begin{array}{l}\text { (Schwanninger et al., 2011; Sandak et al., 2013) } \\
\text { (Popescu et al., 2018) }\end{array}$ \\
\hline 2 & 4910 & 4904 & $\mathrm{C}, \mathrm{L}$ & C-H def. and O-H str. & (Popescu et al., 2018) \\
\hline \multirow[t]{3}{*}{3} & 4675 & 4686 & $\mathrm{H}$ & $\mathrm{C}-\mathrm{H}$ str. $+\mathrm{C}=\mathrm{O}$ str. & (Schwanninger et al., 2011) \\
\hline & & 4686 & $\mathrm{~L} / \mathrm{E}$ & $\mathrm{C}_{\mathrm{ar}}-\mathrm{H}$ str. $+\mathrm{C}=\mathrm{C}$ str. & (Schwanninger et al., 2011) \\
\hline & & 4679 & $\mathrm{C}, \mathrm{H}$ & C-H str. & (Popescu et al., 2018) \\
\hline 4 & 4436 & 4435 & All & O-H str. + C-O str. & (Schwanninger et al., 2011) \\
\hline 5 & 4382 & 4392 & $\mathrm{C}$ & $\begin{array}{l}\text { O-H str. + C-C str. and/or } \\
\text { C-H str. + C-H def. }\end{array}$ & (Schwanninger et al., 2011) \\
\hline 6 & 4316 & 4319 & & $\mathrm{C}-\mathrm{H}_{2}$ & (Sandak et al., 2015) \\
\hline 7 & 4204 & 4202 & Holo & $2^{\text {nd }}$ OT O-H def. & (Schwanninger et al., 2011) \\
\hline 8 & 4104 & 4100 & & $\mathrm{C}-\mathrm{H}$ def. and $\mathrm{O}-\mathrm{H}$ str. & (Sandak et al., 2015) \\
\hline
\end{tabular}

Table 4. Summary of the results of the different type of variable selection techniques for modulus of elasticity prediction. The best model is highlighted in italics.

\begin{tabular}{lccccccc} 
& LVs & RMSECV & $\mathbb{R}^{2}$ & Slope & Bias & RER & RPD \\
PLS & 8 & 783.10 & 0.72 & 0.6895 & 14.4678 & 9.86 & 1.89 \\
rPLS & 8 & 736.54 & 0.75 & 0.7161 & -3.6001 & 10.49 & 2.01 \\
\hline$i P L S$ 100 for & 8 & 696.01 & 0.78 & 0.7815 & -1.2286 & 11.10 & 2.13 \\
iPLS 50 for & 10 & 720.36 & 0.76 & 0.7245 & -2.0282 & 10.72 & 8.37 \\
\hline iPLS 100 back & 8 & 922.79 & 0.62 & 0.5592 & -6.1199 & 6.19 & 1.61 \\
iPLS 50 back & 3 & 1248.48 & 0.29 & -28.0397 & 0.2628 & 1.19 \\
\hline VIP & 7 & 820.35 & 0.69 & 0.6558 & 2.7618 & 9.42 & 1.81 \\
\hline
\end{tabular}

LVs, number of latent variables; RMSECV, root mean square error of cross validation; RER, range error ratio; RPD, ratio of performance to deviation; PLS, partial least squares; rPLS recursive weighted PLS; iPLS, interval PLS; VIP, variables important in projections. 
and from 4440 to $4386(14) \mathrm{cm}^{-1}$, in which different chemical bonds (C-H, C-O, C-C, C-H-O, O-H) are located. Cellulose and hemicellulose are homogenously distributed, from 6812 to 6700 (5) $\mathrm{cm}^{-1}$ and from 4902 to 4848 (12) $\mathrm{cm}^{-1}$, in contrast to the presence of lignin at the following interval ranges: 7865-7452 (3) $\mathrm{cm}^{-1}$, $5828-5658 \mathrm{~cm}^{-1}$ (9), 4787-4617 cm $\mathrm{cm}^{-1}$ (13), 4440-4386 (14) $\mathrm{cm}^{-1}$ and 4324-4270 (15) $\mathrm{cm}^{-1}$.

Further comparative analysis revealed that MOE selected variables corresponded mostly to those reported in previous works. The presence of cellulose, hemicellulose and lignin influences physical and mechanical wood characteristics, and therefore compression and stress reactions (Fujimoto et al., 2007; Popescu et al., 2018). Wood biological degradation and hygroscopic behaviour are mostly related to cellulose and hemicellulose content, improving stiffness and tensile strength (Fujimoto et al., 2007; Guo and
Altaner, 2018). In particular, it was demonstrated that bending strength depends mainly on cellulose presence, instead of lignin, which plays an active role in increasing compression strength thanks to hydrophobic component (Sandak et al., 2013). Hemicellulose can affect wood resistance reducing the MOE value, but amorphous cellulose region increases MOE resistance, depending on its amount and quality (Fujimoto et al., 2007). Cellulose fibre orientation in cells layers can improve mechanical properties, while lignin cell walls layers ( $\mathrm{H}$ bonds between microfibrils) can influence wood strength (Guo and Altaner, 2018). Considering the differences in mechanical and physical properties between wood species due to their chemical components, cellulose crystallinity affects density that increases in hardwood rather than in softwood species, whereas density increases with the presence of amorphous region of cellulose (Alves et al., 2012).

A

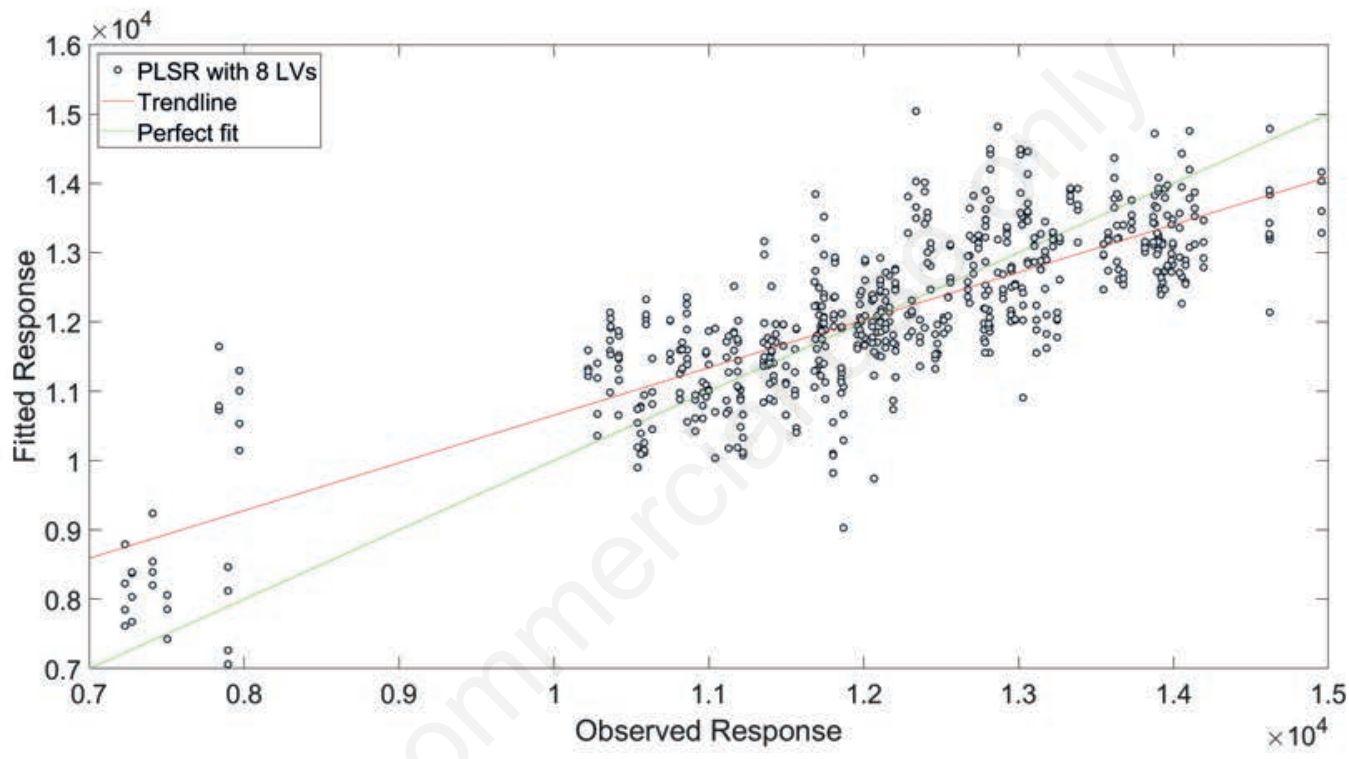

B

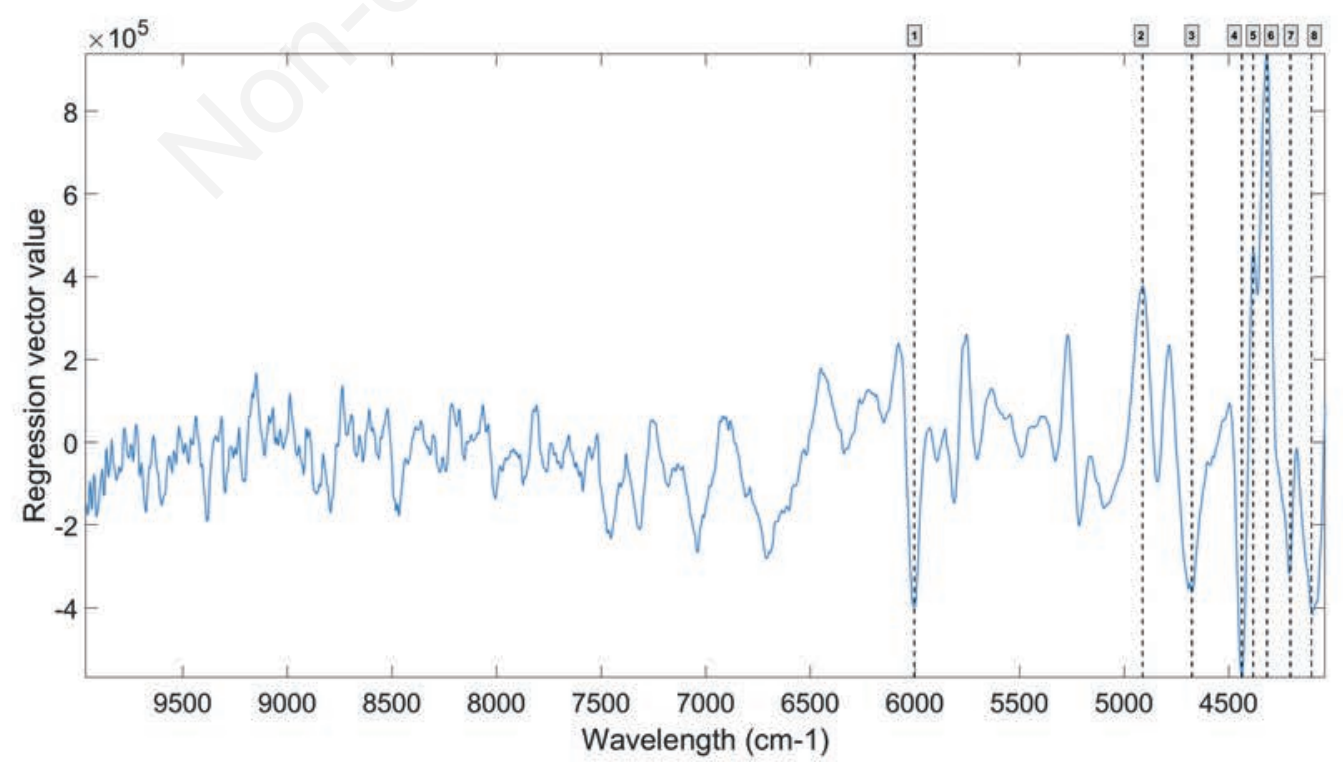

Figure 2. A) Partial least squares regression (PLSR) plot for the prediction of modulus of elasticity. The spectra were pre-processed by a first order derivation using the Savitzky-Golay algorithm with 21 smoothing points and 8 latent variables (LVs); B) corresponding regression vector plot using vertical lines and numbering to discriminate the most important wavelengths 


\section{Prediction of modulus of rupture and density}

PLS models for MOR prediction are less fitting $\left(\mathrm{R}^{2}=0.39\right)$ and cannot be used for quality assessment applications. Similarly, PLS models for $\mathrm{D}$ prediction, even with higher coefficient of determination $\left(\mathrm{R}^{2}=0.52\right)$, cannot be used as a screening tool. It was demonstrated that mechanical features assessment is more difficult for chestnut wood than for other species, due to its high variability in physical characteristics during growth processes (Romagnoli et $a l ., 2014)$. The results confirmed that mechanical and physical characteristics of chestnut wood do not easily correlate and density can be a limit to strength assessment (Nocetti et al., 2016) and to visual grading classification (Brunetti et al., 2013). In fact, chestnut wood density is influenced by tree-ring width, in relation to growth variability and forest management (Romagnoli et al., 2014) according to the European grading standards (Brunetti et al., 2013). The great variability of chestnut wood is also confirmed by Duca et al. (2016). In this study based on spectroscopy analysis, sweet chestnut wood resulted to be more scattered in PCA score plot than other hardwood and softwood species. In addition, it is important to note an under-representation of studies on hardwood analysis with NIR technique, in comparison to softwood analysis. In literature, several Pinus species were used to study the possibility to predict mechanical and physical features with NIR technology (Kelley et al., 2004; Fahey et al., 2018; Guo and Altaner, 2018). Fujimoto et al. (2007) developed strength prediction models on Larix species, while Yu et al. (2009), Barré et al. (2018), Popescu et al. (2018) and Sandak et al. (2013) obtained good results with different Abies species. Fewer are the NIR analysis applications on hardwood species: on Populus clones (Horvath et al., 2011), on Tilia cordata (Popescu and Popescu, 2013), on Eucaliptus (Pfautsch et al., 2012). The last two studies are only related to thermic analysis. Based on these results, it is necessary to improve the assessment of NIR applications to hardwood species.

Given the high correlation $\left(\mathrm{R}^{2}=0.94\right)$ between MOE and $\mathrm{P}$, the results obtained can be considered satisfactory also for the predic- tion of P parameter. The PLS regression model returned the following values: $\mathrm{R}^{2}=0.71, \mathrm{RMSECV}=20.07 \mathrm{~N} / \mathrm{mm}, \mathrm{RER}=9.57$ and $\mathrm{RPD}=1.86$. Better outputs were obtained using the forward iPLS (100 segments) variable selection technique. $\mathrm{R}^{2}$ increased to 0.80 , as well as RER that increased to 11.42 and RPD to 2.23; RMSECV decreased to $16.81 \mathrm{~N} / \mathrm{mm}$. These results suggest the possibility to predict $\mathrm{P}$ instead of MOE parameter in order to remove the size variability with different samples sections.

\section{Conclusions}

This study demonstrated the suitability of NIR technique and multivariate data analysis for the prediction of MOE of Castanea sativa wood samples. A good PLS model was obtained and the prediction performance could be improved using forward iPLS (with 100 segments), making the model suitable for screening applications. Regression vector plot and the variables selected by iPLS technique were used to detect the more reliable wood compounds for the assessment of wood mechanical properties. The results are consistent with the literature and they confirm the importance of cellulose and lignin for MOE prediction. In addition, it was proved that MOR and D prediction models cannot be used for screening quality applications on chestnut wood samples. Instead, given the high correlation between MOE and P, a good PLS regression model was obtained for $\mathrm{P}$ prediction.

This study provides further contributions for fostering NIR as a non-destructive and rapid technique for predicting the mechanical quality of wood. To take into consideration that the assessment on chestnut wood is more difficult than on other species and further analysis should be carried out to test specific models on chestnut wood and on different hardwood species. Considering its high quality, chestnut wood could be used for different applications in order to enhance its exploitation. The improvement of the NIR method in the sector is huge. In fact, such method could be used for the rapid

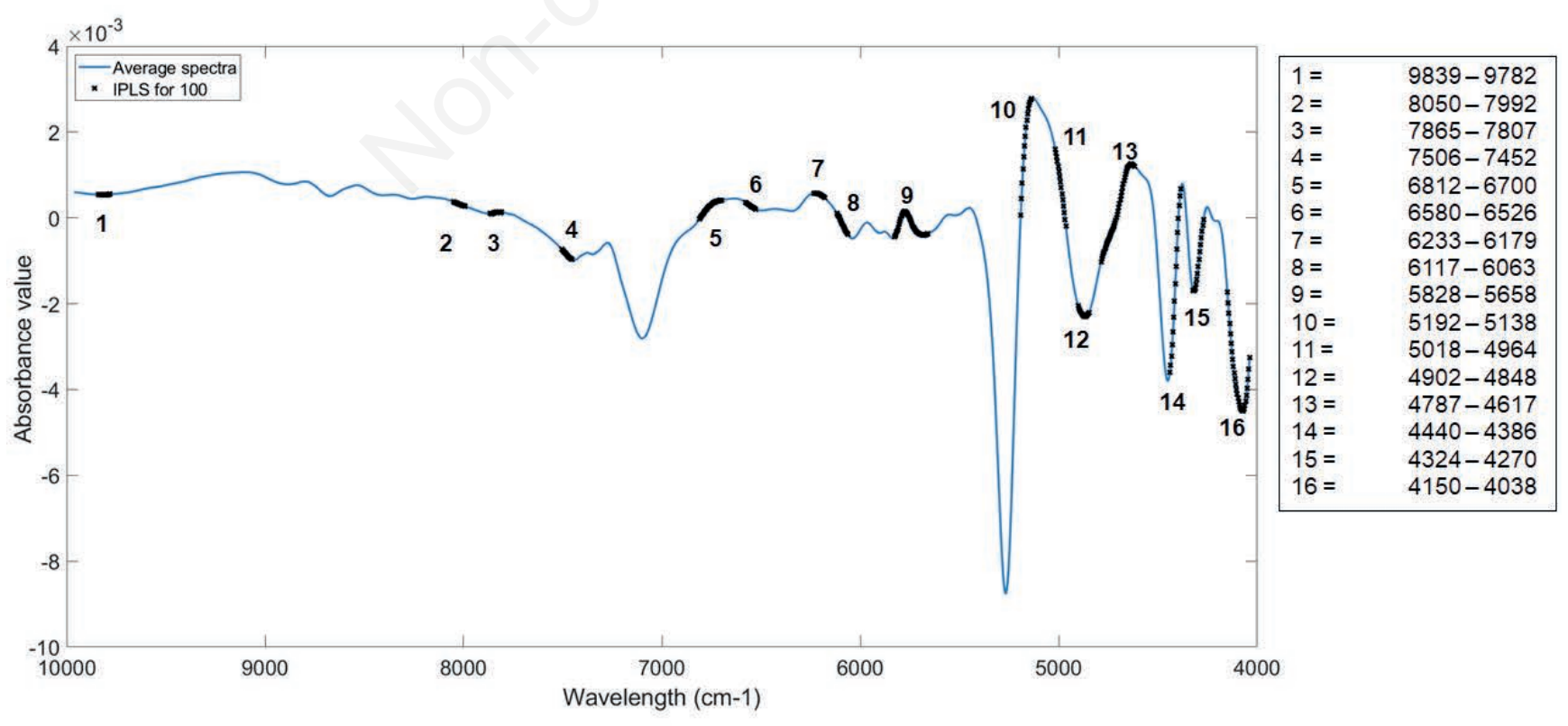

Figure 3. Variable selected by interval partial least squares (iPLS) system for modulus of elasticity prediction. 
assessment of the wood quality avoiding the sample destruction. In addition, the application of NIR technique directly on-situ could improve analysis on standing trees, effectively reducing operation charges, time for investigation and sample preparation.

\section{References}

Alves A., Santos A., Rozenberg P., Pâques L.E., Charpentier J.P., Schwanninger M., Rodrigues J. 2012. A common near infrared-based partial least squares regression model for the prediction of wood density of Pinus pinaster and Larix $\times$ eurolepis. Wood Sci. Technol. 46:157-75.

Barré J.B., Bourrier F., Cécillon L., Brancheriau L., Bertrand D., Thévenon M.F., Rey F. 2018. Predicting mechanical degradation indicators of silver fir wooden strips using near infrared spectroscopy. Eur. J. Wood Wood Prod. 76:43-55.

Brunetti M., Nocetti M., Burato P., Bacher M., Berti S. 2013. Strength properties of chestnut structural timber with wane. Adv. Mater. Res. 778:377-84.

Duca D., Mancini M., Rossini G., Mengarelli C., Foppa Pedretti E., Toscano G., Pizzi A. 2016. Soft independent modelling of class analogy applied to infrared spectroscopy for rapid discrimination between hardwood and softwood. Energy. 117:251-8.

Fagan C.C., Everard C.D., McDonnell K. 2011. Prediction of moisture, calorific value, ash and carbon content of two dedicated bioenergy crops using near-infrared spectroscopy. Bioresour. Technol. 102:5200-6.

Fahey L.M., Nieuwoudt M.K., Harris P.J. 2018. Using near infrared spectroscopy to predict the lignin content and monosaccharide compositions of Pinus radiata wood cell walls. Int. J. Biol. Macromol. 113:507-14.

Fujimoto T., Matsumoto K., Kurata Y., Tsuchikawa S. 2007. Rapid and nondestructive evaluations of wood mechanical properties by near infrared spectroscopy. J. Near Infrared Spectrosc. 16:529-37.

Guo F., Altaner C.M. 2018. Molecular deformation of wood and cellulose studied by near infrared spectroscopy. Carbohydr. Polym. 197:1-8.

Horvath L., Peszlen I., Peralta P., Kelley S. 2011. Use of transmittance near-infrared spectroscopy to predict the mechanical properties of 1- and 2-year-old transgenic aspen. Wood Sci. Technol. 45:303-14.

Kelley S.S., Rials T.G., Snell R., Groom L.H., Sluiter A. 2004. Use of near infrared spectroscopy to measure the chemical and mechanical properties of solid wood. Wood Sci. Technol. 38:257-6.

Macchioni N., Pividori M. 1996. Ring shake and structural characteristics of a chestnut (Castanea sativa Miller) coppice stand in northern Piedmont (northwest Italy). Ann. des Sci. For. 53:31-50.

Nocetti M., Brunetti M., Bacher M. 2016. Efficiency of the machine grading of chestnut structural timber: prediction of strength classes by dry and wet measurements. Mater. Struct. Constr. 49:4439-50.

Norgaard L., Saudland A., Wagner J. 2000. \{Interval partial leastsquares regression (iPLS): a comparative chemometric study with an Vldots \}. Appl. Spectrosc. 54:413-9.

Pfautsch S., Macfarlane C., Ebdon N., Meder R. 2012. Assessing sapwood depth and wood properties in Eucalyptus and Corymbia spp. using visual methods and near infrared spectroscopy (NIR). Trees - Struct. Funct. 26:963-74.

Popescu C.M., Navi P., Placencia Peña M.I., Popescu M.C. 2018. Structural changes of wood during hydro-thermal and thermal treatments evaluated through NIR spectroscopy and principal component analysis. Spectrochim. Acta - Part A Mol. Biomol. Spectrosc. 191:405-12.

Popescu C.M., Popescu M.C. 2013. A near infrared spectroscopic study of the structural modifications of lime (Tilia cordata Mill.) wood during hydro-thermal treatment. Spectrochim. Acta - Part A Mol. Biomol. Spectrosc. 115:227-33.

innan Å., Andersson M., Ridder C., Engelsen S.B. 2014. Recursive weighted partial least squares (rPLS): An efficient variable selection method using PLS. J. Chemom. 28:439-47.

Rinnan A., Berg F., Engelsen S. 2009. Review of the most common pre-processing techniques for near-infrared spectra. TrAC-Trends Anal. Chem. 28:1201-22.

Romagnoli M., Cavalli D., Spina S. 2014. Wood quality of chestnut: Relationship between ring width, specific gravity, and physical and mechanical properties. BioResour. 9:1132-47.

Sandak A., Rozanska A., Sandak J., Riggio M. 2015. Near infrared spectroscopic studies on coatings of 19th century wooden parquets from manor houses in South-Eastern Poland. J. Cult. Herit. 16:508-17.

Sandak J., Sandak A., Pauliny D., Krasnoshlyk V., Hagman O. 2013. Near infrared spectroscopy as a tool for estimation of mechanical stresses in wood. Adv. Mater. Res. 778:448-53.

Schwanninger M., Rodrigues J.C., Fackler K. 2011. A review of band assignments in near infrared spectra of wood and wood components. J. Near Infrared Spectrosc. 19:287-308.

Sørensen L.K. 2009. Application of reflectance near infrared spectroscopy for bread analyses. Food Chem. 113:1318-22.

Sousa H.S., Branco J.M., Lourenço P.B. 2014. Prediction of global bending stiffness of timber beams by local sampling data and visual inspection. Eur. J. Wood Wood Prod. 72:453-61.

Toscano G., Rinnan A., Pizzi A., Mancini M. 2017. The use of nearinfrared (NIR) spectroscopy and principal component analysis (PCA) to discriminate bark and wood of the most common species of the pellet sector. Energy \& Fuels 31:2814-21.

Tsuchikawa S., Kobori H. 2015. A review of recent application of near infrared spectroscopy to wood science and technology. J. Wood Sci. 61:213-20.

Watkins D., Nuruddin M., Hosur M., Tcherbi-Narteh A., Jeelani S. 2015. Extraction and characterisation of lignin from different biomass resources. J. Mater. Res. Technol. 4:26-32.

Wold S., Sjostrom M. 1977. SIMCA: a method for analysing chemical data in terms of similarity and analogy. pp 243-282 in ACS (A c. di), Chemometrics: theory and application. American Chemical Society, Washington, DC, USA.

Wold S., Sjostrom M., Eriksson L. 2001. PLS-regression: a basic tool of chemometrics. Chemom. Intell. Lab. Syst. 58:2001-109.

Yu H., Zhao R., Fu F., Fei B., Jiang Z. 2009. Prediction of mechanical properties of Chinese fir wood by near infrared spectroscopy. Front. For. China 4:368-73. 